\title{
El recordar juntos: desafíos de la memoria en educación
}

\section{Remembering together: Challenges of memory in education}

\section{Jairo Hernando Gómez Esteban ${ }^{1}$}

\begin{abstract}
Pero cuando nada subsiste ya de un pasado antiguo, cuando han muerto los seres y se han derrumbado las cosas, solos, más frágiles, más vivos, más inmateriales, más persistentes y más fieles que nunca, el olor y el sabor perduran mucho más, y recuerdan, y aguardan, y esperan, sobre las ruinas de todo, y soportan sin doblegarse en su impalpable gotita el edificio enorme
\end{abstract} del recuerdo.

Marcel Proust

Por el camino de Swann

\section{Resumen}

La concepción de memoria analizada desde dos perspectivas, una psicológica y otra como proceso colectivo, y teniendo en cuenta la influencia por la introducción de tecnologías en el contexto cotidiano, deja entrever que la educación adquiere un papel importante al formar el puente que comunica estas instancias, pues ellas hacen parte de la construcción de identidades y subjetividades en nuestros días. Por ello, el siguiente artículo propone analizar estas casi antagónicas concepciones sobre la memoria y sus implicaciones teóricas y metodológicas -más no didácticas- en la educación.

\section{Palabras clave:}

Memoria informatizada, memoria colectiva, codificación de identidad, reconstrucción social, educación.

\section{Abstract}

The conception of memory analyzed from two perspectives, one of these being psychological and the other one being a collective construction, and taking into account the influence of new technologies that exist in our current context, shows that education has a very important role because it is considered to be the bridge between these two conceptions, as both of them are essential parts of identity and subjectivity construction today. As a result, the purpose of the following article is to analyze these two points of view about memory and its methodological and theoretical implications in education.

Keywords:

Computerized memory, collective memory, construction of identity, social reconstruction, education.

Artículo recibido el 22 de agosto de 2010 y aprobado el 28 de marzo de 2011

1 Profesor de la Maestría en Investigación Social Interdisciplinaria de la Universidad Distrital Francisco José de Caldas 


\section{Introducción}

Probablemente se recordará, que la evocación que Swann hace a través de la magdalena en el conocido pasaje de la novela de Proust, es el rescate de la memoria subjetiva, de aquella forma de expresión absolutamente singular que ahonda en los más recónditos y personales recuerdos. Proust nos ilumina con una historia, con el más grande relato -siete tomos- jamás escrito sobre la memoria. Esta memoria prodigiosa y poética, nos revela cómo el recuerdo no sólo configura nuestra identidad, sino también, si se emplean los métodos y conceptos adecuados, se puede constituir en la vía más plausible para adelantar cualquier proceso deconstructivo de nuestra subjetividad. Otro tanto ocurre con Funes el memorioso, el célebre cuento de Borges en el que se nos revela cómo una hipertrofia de la memoria, no sólo impide pensar, sino ser, estar ahí, moviéndose como lo hacemos todos, con una enorme capacidad de olvido, por fortuna, de todo lo que no es digno de llamar nuestra atención. Borges nos muestra que un exceso de memoria impide cualquier abstracción y generalización, cualquier razonamiento o subjetivación; no sin razón Umberto Eco (1999) denomina a la Web como ese inmenso Funes, en la que es posible perderse si no hay un buen filtrado, para lo cual es necesario una papelera donde arrojar la basura, un lugar donde olvidar.

Nuestra papelera es el inconciente, el cual opera no sólo para albergar lo reprimido, sino como filtro de lo que se recicla, o, definitivamente, se olvida. Pero no sólo el inconciente funciona como mecanismo de selección subjetiva de la memoria. Con el advenimiento de la memoria informatizada de la Web, los mecanismos de filtración de la información quedan determinados por la experticia tecnológica y el conocimiento de la materia. A esta memoria informatizada, que requiere un gran depósito para arrojar tanta basura, que exige precisión y se mueve en un eterno presente, que se tiene que adaptar a un mundo volátil de cambios abruptos y, a veces, erráticos, a esta memoria de la velocidad y la simul- taneidad se opone la memoria colectiva ${ }^{2}$, la memoria como imperativo categórico (Tafalla, 2000), las luchas de la memoria por preservar el recuerdo, para no arrojar a la papelera de la Historia esas injurias a la humanidad y a la dignidad, como los genocidios de las fuerzas paraestatales, de las dictaduras militares de todos los pelambres, de los campos de concentración nazi, de la inquisición y las cruzadas, en fin, el recuerdo del dolor, del crimen y del terror. "La memoria empieza en el terror", sentencia Cortázar (citado por Braunstein, 2008) al comienzo de su relato autobiográfico, como previniendo que el terror y el miedo no sólo actualizan los recuerdos personales y subjetivos, sino también, las huellas de dolor y de trauma que la humanidad ha tenido y seguirá teniendo a lo largo de la Historia.

El propósito de este trabajo es contraponer estas dos perspectivas casi antagónicas de la memoria y, a partir de su tematización y discusión, establecer algunas implicaciones teóricas y metodológicas en educación. ¿Cómo conciliar o, al menos, establecer vasos comunicantes mínimos entre esa memoria vertiginosa que requiere procesar ingentes volúmenes de información, cuyas repercusiones en la identidad y la subjetividad son aun imprevisibles, con esa memoria ética o histórica de la que se ocupan las diversas tendencias de la memoria colectiva (Serna, 2009), con esa memoria que pugna por preservarse a través de la lucha, la denuncia, la conmemoración, el monumento y, sobre todo, por la recordación boca a boca, por la remembranza oral de la narrativa que cuenta lo que sucedió? De igual forma, también debe considerarse en esta problemática la memoria subjetiva, la memoria proustiana que rememora las experiencias singulares y se retrotrae a los recuerdos primigenios: quizás sea esta memoria la clave para entender los mecanismos de ese dispositivo de filtración que permite olvidar o recordar no sólo

2 Naturalmente que esta diferenciación es arbitraria y puramente analítica, en tanto cuanto la memoria colectiva está imbricada en la memoria informatizada y viceversa. Lo que se pretende es subrayar y antagonizar la diferencia entre las dos perspectivas más generales en el estudio de la memoria: la cognitivo-computacional anclada en la psicología, y la socio-histórica y ética, apoyada en diversas disciplinas sociales o enfoques interdisciplinarios. 
nuestras experiencias vividas, sino también, nuestras vivencias imaginadas o ficcionalizadas.

Las implicaciones educativas del estudio de la memoria en sus diversas expresiones -informatizada, colectiva o subjetiva- no pueden reducirse a la discusión de un proceso didáctico (la enseñanza de la Historia o de la tecnología), así como tampoco a meros ejercicios intelectuales o mnemotécnicos. Por tanto, se hace necesario explicitar y relacionar los diversos enfoques del estudio de la memoria, tanto disciplinares como políticos, para discutir con propiedad sus implicaciones educativas. De esta forma, se presenta inicialmente la perspectiva psicológica para retomar de allí algunos elementos que puedan servir de puente (sobre todo, desde el enfoque de la psicología social, esto es, el de la memoria compartida) con la memoria colectiva y la memoria subjetiva. A continuación se plantean algunas perspectivas de la memoria colectiva, destacando sus luchas contra el olvido que quieren imponer los regímenes del terror, las manipulaciones coloniales o estatales, las políticas culturales o sus usos como recurso para la reconciliación y la reconstrucción de tejido social. Seguidamente se consideran algunos elementos básicos de la memoria subjetiva y su relación con la memoria informatizada, para concluir con algunas implicaciones educativas de la memoria a partir de lo expuesto.

\section{Psicología de la memoria: entre la codificación individual y la reconstrucción social}

Fueron necesarios muchos experimentos y, sobre todo, un cambio de perspectiva epistemológica y metodológica, para que la psicología derribara $-\mathrm{y}$ superara ella misma- el viejo mito que consideraba a los recuerdos como registros pasivos o literales de la realidad. Entender que aspectos tales como el contexto, el significado y las emociones están inextricablemente asociados al recuerdo y el olvido, y resultan imprescindibles para los procesos de codificación y sistematización de la información, constituyó un gran paso -a pesar de su obviedad- en el estudio experimental de la memoria.
Una de las razones para que se haya reconocido esta pluralidad de factores que inciden en la memoria como proceso psicológico es que, tras años de seguir caminos separados, los psicólogos cognitivos, los psicólogos clínicos (incluidos los psicoanalistas) y los neurocientíficos lograron ponerse de acuerdo y desarrollar un enfoque integral de la memoria. No obstante, la perspectiva psicológica y neurológica de la memoria sigue centrada en las disfunciones, patologías y trastornos presentados en individuos que han sufrido algún tipo de accidente o traumatismo físico o psicológico.

En términos generales, la psicología concibe la memoria humana como una especie de dispositivo que procesa información y, a semejanza de un computador, registra, almacena y recupera datos. Esta memoria computacional es lo que he denominado como memoria informatizada, la cual se circunscribe a un proceso puramente cognitivo en el cual aspectos tales como el contexto del recuerdo, las emociones y sentimientos, o los códigos éticos en la selección de la información, son tomados como variables que eventualmente pueden afectar el proceso mnemónico. Ahora bien, para explicar los diversos tipos de recuperación o almacenamiento de la información, los psicólogos (Shacter, 1999) han denominado como memoria semántica aquella que contiene conceptos y hechos, y memoria de procedimiento, la que nos permite desarrollar capacidades y adquirir hábitos. Habría que agregar a las anteriores la memoria episódica, propuesta por Endel Tulving (citado por Shacter, 1999), la cual nos permite recordar explícitamente los incidentes personales que constituyen nuestra singularidad. De igual forma, habría que anotar la distinción hecha, sobre todo desde el psicoanálisis freudiano, entre la memoria de campo y la memoria de observador. En efecto, fue Freud el primero en afirmar que los recuerdos de observador, es decir, los recuerdos en los que aparecemos como observadores ajenos, necesariamente eran versiones alteradas de la vivencia original, ya que la percepción o sensación primigenia se produce siempre desde una perspectiva de campo determinada. Por tanto, la perspectiva de campo se centra en los sentimientos y emociones que se vivenciaron 
en el momento mismo del registro, mientras que la perspectiva de observador tiene en cuenta, por así decirlo, las "circunstancias objetivas" del acontecimiento. De esta forma, recordar un incidente, evento o acontecimiento, dependerá de la forma como hayamos registrado, emocionalmente hablando, ese acontecimiento, y de la clase de información que podamos traer a la mente al rememorarlo.

Ahora bien, gran parte de los argumentos de los psicólogos cognitivos de la memoria informatizada, se basa en la analogía que ellos establecen entre la memoria y el sofware de los computadores. Según ellos (por ejemplo Newell, 1980, Pascual Leone, 1984 y muchos más), no se puede negar la isomorfía que existe entre el procesamiento de información y la manera como operan e interactúan las neuronas con los chips de silicio y los cables de un computador. Esta analogía los ha llevado a diseñar sofisticados experimentos, al punto que los defensores más acérrimos de la Inteligencia Artificial han llegado a afirmar que en un futuro muy próximo los computadores tendrán las mismas capacidades de la mente humana, con un yo y una subjetividad incluida ${ }^{3}$.

Aunque para muchos la idea de que la conciencia humana es idéntica a un hardware y sus mecanismos son isomórficos a los del procesamiento de información de la mente, puede resultar muy atractiva; lo cierto es que esta discusión logra ayudarnos a entender si toda recuperación de información o, incluso, cualquier recuerdo, implica una experiencia conciente de recordar y una reconstrucción de nuestra identidad. Además, queda pendiente la otra cara de la memoria: el afuera, la situación o contexto concreto en que se registra el acontecimiento, la valoración social que éste tiene $y$, sobre todo, la legitimación y refrendación que el otro exige del recuerdo. Esta otra cara de la memoria, su carácter social y compartido, es la que se ha estudiado desde el punto de vista de la psicología social, el

3 Son muchos, y desde diferentes perspectivas, los detractores y críticos de la analogía e isomorfia entre la mente humana con el computador. Quizás los más contundentes y mejor argumentados sean Searle (1994) y Penrose (1991). interaccionismo simbólico, la psicología cultural y las diferentes corrientes neovigotskianas ${ }^{4}$.

En efecto, a pesar de que el estudio de la memoria como proceso social aún no ha recibido la atención que se merece por la investigación psicológica canónica y dominante, es un hecho que sin esta perspectiva social no se podrá entender jamás cómo los actores sociales reconstruyen sus recuerdos de una forma determinada y en un momento dado. Es por eso que se parte del presupuesto que el recuerdo está mediatizado socialmente y no se limita a un proceso puramente individual, que nuestra capacidad de recordar y olvidar se desarrolla conjuntamente, de manera compartida, unas veces a través de la institucionalización social del olvido, otras, por la amnesia instigada estructuralmente. Aquí los problemas ya no se centran en los mecanismos de procesamiento y recuperación de la información, sino en la forma como las personas comparten recuerdos, en el proceso de evocar experiencias colectivas y la manera como registran eventos que serán recordados y conmemorados en ocasiones futuras. En este sentido, sus trabajos se orientan por las prácticas sociales de conmemoración, el contexto social de la memoria individual, la organización retórica del recuerdo y el olvido (esto es, sobre las versiones contradictorias del pasado: a quién culpar, perdonar, agradecer, etc.), el recuerdo y el olvido institucional y las prácticas sociales de la memoria.

El recordar juntos se constituye entonces en el objetivo principal de esta perspectiva psicosociológica de la memoria. Para dilucidar este proceso se entiende que en "el proceso de evocar distintas experiencias compartidas, la gente reinterpreta y descubre rasgos del pasado que devienen contexto y contenido de lo que recordarán y conmemorarán juntos en ocasiones futuras" (Middleton y Ed-

4 Este enfoque psicosociológico de la memoria se ocupa básicamente de la construcción social del recuerdo y el olvido, el olvido organizacional, el recuerdo conversacional, y, en fin, de la memoria social de los individuos. Su énfasis está en los objetos y los contextos que posibilitan la evocación, en el carácter distribuido de la memoria y en los artefactos sociales que promueven el recuerdo y el olvido. David Middleton y Derek Edwards (1992) son sus mayores exponentes y difusores, y es en este libro en el que se apoya este apartado. 
wards, 1992, p. 23). De igual forma, se recurre a las denominadas prácticas sociales de conmemoración las cuales, a partir de la celebración de un hecho o una persona, configuran la identidad y concepción cultural y generacional de un grupo de personas determinado. En la reconstrucción conjunta del pasado (el recordar juntos), uno de los problemas más acuciantes es el del carácter "verdadero" o "correcto" acerca de lo que pasó o no, es decir, sobre las versiones contradictorias del pasado. A este problema se le ha denominado la organización retórica del pasado en tanto

\begin{abstract}
la "verdad" del pasado siempre es, al menos potencialmente, cuestionable. No se encuentra claramente depositada en ningún informe ni archivo social objetivo, ni tampoco resulta infinitamente maleable al servicio del presente. No se obtiene como "hecho" ni como "invención", sino como logro epistemológico creado mediante la dialéctica y la discusión entre posturas contrarias" (Middleton y Edwards, 1992, p. 25).
\end{abstract}

En El libro de la risa y el olvido de Milan Kundera, se narra cómo un líder comunista-Clementis-fue literalmente borrado de las fotos oficiales, los manuales escolares y los museos de la Checoslovaquia comunista, luego de ser acusado de traición. Nadie se explicaba después cómo un hombre, que había sido elevado a las más altas dignidades patrióticas, se borraba de un tajo de la historia del país. Este caso ilustra muy bien otra de las preocupaciones de la reconstrucción conjunta de la memoria social: la manipulación a gran escala -en este caso, desde el Estado mismo- de lo que debe o puede ser recordado por una comunidad o, incluso, por una nación entera. No sin razón un personaje del relato de Kundera dice: "la lucha del hombre contra el poder es la lucha de la memoria contra el olvido". El recuerdo y el olvido institucional, que es como se denomina este proceso de manipulación y tergiversación de la memoria desde las diversas instancias de poder, tiene mucho que ver con la "comunidad de recuerdos" (community of memory) de la que habla Bellah (1985, citado por Middleton y Edwards, 1992, p. 21), la cual se refiere al contexto de significado constituido por el pasado "en un sentido básico", esto es, a la necesidad de olvidar o recordar sistemáticamente con base en los emplazamientos políticos y culturales de la memoria colectiva de cada comunidad.

Uno de los aspectos fundamentales del recordar juntos lo constituye la integración a una determinada modalidad de práctica social; en efecto, dicha integración es lo que posibilita darle coherencia y sentido de continuidad a nuestra existencia. Desde este punto de vista, la identidad e integridad de la mente de una persona depende de su participación e integración en un entorno sociocultural específico, en donde la memoria individual se vuelve indisociable de la memoria colectiva y la significación de los recuerdos queda subsumida en el universo simbólico de dichas prácticas sociales. En esta atribución de sentido y significado colectivo de los recuerdos juegan un papel fundamental los artefactos sociales. En la novela La misteriosa llama de la reina Loana, de Umberto Eco, se ilustra claramente este concepto. Yambo, el personaje principal, ha perdido su memoria personal, la más ligada a las emociones, en un accidente. No sabe quién es, ni recuerda su nombre, su familia, ni su profesión; no obstante, recuerda libros, personajes, películas, datos históricos $\mathrm{y}$, sobre todo, tebeos, que son los que finalmente le van a permitir revivir sus emociones primigenias más subjetivas y singulares, reconstruir su infancia $y$, en consecuencia, reestablecer su identidad. Es la demostración casi clínica de que la memoria está en las cosas, en objetos a los que nuestro yo se ha adherido, se ha distribuido, se ha imbricado. Por tanto, es el uso rememorativo y reconstructivo de aquellos objetos que no sólo nos evocan las experiencias y emociones más profundas y personales -como la magdalena de Proust-, sino también, esa grata sensación que revivimos de continuidad y preservación de nuestra propia identidad, lo que constituye la principal función de los artefactos sociales de la memoria.

Esta perspectiva psicosociológica de la memoria abre excelentes posibilidades de investigación en educación, ya que posibilita establecer vasos comunicantes entre la memoria individual y la memoria colectiva, a la vez que complementa y contextualiza, 
social e históricamente, la limitada perspectiva cognitivista y algorítmica de la psicología de la memoria canónica y dominante. Sin embargo, es necesario revisar las diversas perspectivas políticas y sociológicas de la memoria: sus luchas, sus compromisos éticos, sus reivindicaciones, sus usos sociales, sin las cuales no es posible realizar ninguna reflexión educativa.

\section{Las tribulaciones de la memoria colectiva}

Si la memoria comienza con el terror, como plantea Cortázar, es la memoria la única que puede reconstruir lo que ese terror destruye, rescatando el recuerdo de cada uno de los individuos que sufrieron su indignidad y su violencia, reconstruyendo sus historias personales y sus "comunidades de recuerdos", resarciéndolos de la muerte total y salvándolos del olvido.

El trabajo de la memoria revela que los grandes genocidios y ultrajes a la humanidad ${ }^{5}$ de los regímenes totalitarios de todas las pelambres, que asolaron el mundo durante el siglo XX, han sido el resultado de una historia de poder y dominio y, por tanto, evitar que esos totalitarismos vuelvan a reaparecer no olvidándolos, no ignorándolos, es la principal función histórica de la memoria. Sólo a través de ella se restituye la identidad de las víctimas, sólo con la rememoración se reconstruyen los recuerdos y, en consecuencia, se garantiza la justicia; es la memoria la que preserva nuestra condición humana $y$, por tanto, el sentido de universalidad y dignidad que todos, por el hecho de pertenecer a la especie humana, tenemos el derecho y el deber de mantener. Es éste compromiso ético y político, es ésta obligación histórica, es ésta la lucha de la memoria

5 Aquí resulta fundamental señalar que el llamado sentimiento de humanidad surge muy tardíamente en la historia. Como nos los muestra claramente Finkielkraut (1982) en su lúcido ensayo sobre las diversas formas y evoluciones que ha seguido no sólo la noción teórica, sino sobre todo, las prácticas derivadas de los imaginarios sociales de humanidad, la diferencia siempre ha prevalecido sobre la semejanza. Han tenido que transcurrir muchos siglos para que los hombres se reconozcan unos a otros como especie y aún no se logra del todo por parte de ciertos grupos sociales, e incluso naciones enteras, que se siguen considerando superiores, 0 , como diría George Orwell en su novela Rebelión en la granja, algunos se sienten más iguales que otros. la que Adorno (Tafalla, 2003) ha denominado como el nuevo imperativo categórico.

Mientras que el imperativo categórico kantiano es anterior a la experiencia y sólo puede descubrirse en la razón pura de manera apriorística, y las leyes morales que de él emanan se encuentran sujetas e imbricadas en la racionalidad misma y, en consecuencia, deben cumplir la condición de ser universalizables porque las normas son las mismas para todos; el nuevo imperativo categórico propuesto por Adorno está dictado por la experiencia, sobre todo por la experiencia del $\mathrm{mal}^{6}$, en rechazar esa experiencia, en una dialéctica negativa que se niega a repetir lo sucedido, en una ética que dice no a la repetición del horror y a la destrucción de la dignidad, que se solidariza con el sufrimiento de los cuerpos, con el dolor de los otros. Pero para que ésta ética realmente tenga sentido y sea incorporada a nuestra subjetividad, tiene que estar situada dentro de la Historia, en un tiempo y en un lugar determinado, y para ello tiene que estar llena de memoria, que es la que tiene la capacidad de señalar el mal bajo una forma concreta para evitar su repetición, y es ahí donde alcanza su pretensión universal:

El mal concreto, el mal particular, puede reaparecer hasta imponerse de un modo general, de un modo total y absoluto. El mal podría universalizarse, y es por ello que la ética es universal. Nos implica a todos, porque todos podríamos ser las víctimas futuras del mal si se repitiera; es así como el nuevo IC vincula a toda la humanidad (Tafalla, 2003, p. 64).

Las luchas por la memoria van desde esas voces que quieren hacerse oír pero que son acalladas porque ya no están aquí, o son descalificadas o desestimadas por su condición social y sólo pueden existir en el diálogo que los recuerda, en la narración

6 Lo que el nuevo imperativo categórico entiende por mal es el dolor y la muerte de tantas personas que han sufrido regímenes de terror. Naturalmente que Adorno se centra en el Holocausto y los campos de concentración judíos, pero sabemos que dicho terror, es decir, que el mal, en su manifestación estructural, no tiene mucha diferencia con el terror y la muerte de los gulags estalinistas, de los regímenes militares de todas las pelambres en América Latina, o de los genocidios y torturas de fuerzas estatales y paraestatales que durante tantos años han asolado nuestro país. 
que se cuenta, en el boca a boca que preserva su recuerdo. Asimismo se expresan en la crítica y la denuncia, como una especie de memoria agonista ${ }^{7}$ que controvierte con la memoria institucionalizada por una verdad vivida y padecida, que se niega a perder la cordura y la integridad ante los embates del olvido que quieren imponer el poder y el Estado. Los combates de la memoria también se dan contra las políticas culturales que quieren convertir la memoria en un instrumento que, "desconectado de la historia de los procesos de expoliación económica, social, política y cultural, terminó convirtiendo la catástrofe del etnocidio en un objeto exótico, transferido a la condición de monumento, de artefacto museístico o de simple imagen de texto" (Serna, 2009 , p. 21). Y, finalmente, las luchas de la memoria también se han manifestado en los procesos de verdad, justicia y reparación que han vivido muchos países, y en donde la memoria colectiva se hace indispensable para la reconciliación, la reclamación de los derechos de quienes han sido despojados de ellos, y la reconstrucción de tejido social.

Ahora bien ¿cómo establecer vasos comunicantes y conciliar entre esta memoria como imperativo categórico con la memoria informatizada que requiere olvidar y enviar a la papelera ingentes cantidades de información porque de otra manera no podría operar con eficiencia y velocidad, tal y como exige esta modernidad líquida que nos avasalla y nos desborda?

\section{Memoria y educación: entre elecciones morales y velocidades interactivas}

La educación en la sociedad contemporánea se enfrenta a unos desafíos que nunca antes había abordado y ni siquiera previsto. La revolución informática y, en general, la subordinación y/o mediación de prácticamente todos los procesos sociales a las tecnologías infocomunicacionales, ha exigido, so pena de hacerse inútil e ininteligible para sus usuarios, una trasformación estructural

7 Entiendo lo agonista en su doble sentido: de combate y de conflicto según los griegos, y de protesta y de denuncia según los humanistas clásicos, desde Erasmo hasta Nietzsche. de todas las instancias del sistema educativo y, en particular, de la disolución, o al menos, de la resignificación de sus códigos éticos y prácticas morales que durante tantos años han estado instituidas. En este sentido, la memoria cobra una importancia inusitada en tanto se constituye en uno de los instrumentos humanos cuya función social posibilita realizar, desde procesos de reconstrucción de lo más subjetivo y singular, hasta aquello que deviene en historia social y memoria colectiva. Es a través de la memoria que el individuo decide qué recuerda -es decir, qué información recupera y conserva-y qué olvida -es decir, que envía al inconciente o a la papelera-, y esta decisión, este proceso de filtración de la información y de la comunicación, es también una elección moral ${ }^{8}$.

Esa posibilidad de elegir un determinado tipo de información, de navegar por ciertos servidores y comunicarse con las redes de interés personal, revela en toda su magnitud la ambigüedad, ambivalencia y falibilidad de lo que Bauman (2005) ha denominado como ética posmoderna. La libertad de elección que tenemos para decidir si seguimos o no las normas y los códigos éticos circulantes y flotantes, si hablamos o no con un grupo de personas, o vemos o no una tipo específico de imágenes, nunca antes la habíamos tenido. La imposibilidad de controlar a los individuos sobre lo que pueden hacer en la Web, nos coloca ante una multiplicidad de elecciones morales que, desde el punto de vista de la memoria, nos lleva a recordar u olvidar lo que la "red de amigos" y la comunidad de recuerdos que

8 En este sentido la web se parece mucho a la biblioteca universal con la que la humanidad siempre soñó, en la que se encontrara reunido todo el conocimiento acumulado, como por ejemplo el "archivo imperial" victoriano que buscaba tener la mayor información posible de sus colonias para ejercer, a su vez, mayor control y dominio. No obstante, la función de la biblioteca universal no sólo sería para dominar. En las más célebres bibliotecas inventadas por la literatura habrían propósitos que van desde mejorar el mundo a través de la ciencia, como las que describe Julio Verne en algunas de sus novelas -por ejemplo en Veinte mil leguas de viaje submarinoo para invocar el mal, la maledicencia y lo siniestro, como en los relatos de Lovecraft, o para demostrar el carácter inalcanzable, infinito y laberíntico del conocimiento, como reiteradamente lo señala Borges en muchos de sus relatos (Abraham, 2006). Huelga decir que estas tres funciones de la biblioteca universal también son aplicables a la red. 
se comparte considera relevante en un momento determinado. Esta relevancia cambia vertiginosamente, incluso antes de que se le haya dado algún uso, lo importante es el significado que tiene en ese momento para quien está en el chat o en Facebook, que pueda ser reconocido y visibilizado por los otros. La información y la comunicación se vuelven mercancías para ser consumidas instantáneamente, en el acto y por única vez, subordinando las elecciones morales a un criterio puramente pragmático, a una necesidad inmediata.

Ahora bien, sería imperdonable entender estas implicaciones de la ética en la memoria sin tener en cuenta los procesos de globalización. En efecto, la desterritorialización inherente a la globalización se expresa en el nomadismo propio de los modos de subjetivación contemporáneos, impulsando principalmente a niños y jóvenes a crear nuevos territorios experienciales y virtuales, ya no para habitarlos y afincarse en ellos, sino para atravesarlos raudos con aventuras de significado, y absorberlos a sus vertiginosos universos simbólicos. Los medios de comunicación y la tecnología informática constituyen las herramientas fundamentales para que estos desplazamientos se produzcan eficientemente. Los fármacos psicoactivos, la meditación del yoga y el budismo, el sexo tántrico y formas complejas de espiritualidad son otras alternativas para alcanzar esas líneas de fuga, para abrirle otras puertas a la percepción. Sin embargo, las culturas mediáticas, a diferencia de las búsquedas espirituales, generalizan y homogeneizan el placer, los gustos, los significados, los símbolos, sin que por ello se despoje a los individuos de su capacidad potencializadora y creadora (Levy,1998 citado por Ryan 2004) y, por eso, a través de los medios de comunicación, "se convierten en agentes significativos de la disolución de los puntos de vista centrales del mundo y promueven una situación explosiva de pluralización que es incontenible" (Rincón, 2006, p. 19).

El principal campo de acción de las culturas mediáticas y los medios de comunicación es el entretenimiento. Como máquinas narrativas que son, le apuestan a los tiempos del ocio, a las veleidades de las emociones y al pensamiento débil. Para lograrlo recurren a todos los artificios técnicos y psicológicos: efectismo, facilismo, predictibilidad, superficialidad, fórmulas, estrellatos débiles, emociones instantáneas. Todas criticadas, denostadas y degradadas; pero todas efectivas, contundentes y eficaces. Al fin y al cabo los juicios de valor estético en las culturas mediáticas son de naturaleza emocional, subjetiva, de gusto y de validez colectiva. Por tanto, para poder ser miembro de esta sociedad se requiere de unos comportamientos y gestos: convertir la vida en una actuación, en una perfomance, en una audición permanente para satisfacer a los otros; tener una filosofía light, en donde se vive para el shopping, la apariencia y la moda; en donde lo importante es el instante, el aquí y el ahora: desarrollar la actitud adecuada y creer a pie juntillas que todo depende de mí, todo está en mis capacidades y en mi interior, es la actitud new age de los manuales de autoayuda y superación personal (Rincón, 2006).

En este proceso de incorporación a la sociedadred, en donde la memoria deviene en múltiples identidades, el cuerpo es probablemente el mayor receptáculo de los embates y asedios de la sociedad del entretenimiento y las culturas mediáticas. Gran parte de los mensajes -explícitos o subrepticios- de los medios de comunicación, apuntan a una transformación y uso no convencional de las corporalidades. Entre estos usos y transformaciones quizás el más evidente e impactante sea el de la espectacularización del cuerpo, o, lo que es lo mismo, el cuerpo como espectáculo.

Los medios de comunicación han descubierto que el cuerpo es la principal máquina de consumo y de exposición social, de tal forma que todas las industrias corporales (alimentarias, cosméticas, médicas, cibernéticas, deportivas, textiles, de la moda, etc.) enfilaron todas sus baterías publicitarias para que el cuerpo fuera mirado como la mercancía más valiosa del individuo y la sociedad. Cuando no logramos que nuestro cuerpo sea observado porque literalmente no da la talla, entonces nos convertimos en espectadores dramatúrgicos para actuar o representar las emociones requeridas de frustración, deseo y, sobre todo, de sorpresa y admiración ante el cambio extremo de los cuerpos. El cuerpo se 
convierte así en un espacio público que quiere ser penetrado, observado, habitado, ocupado, criticado, exaltado o denostado. La intimidad y la sexualidad, como dice Giddens (1995), se ven trasfiguradas en experimentos sociales de cada día, en un infinito reality show en donde lo importante es que haya la mayor cantidad de testigos de dichos experimentos. La clave es la seducción: los cuerpos deben ante todo incitar, fascinar, encantar, "toda su parafernalia narrativa se pone en escena para producir una experiencia evocadora de experiencias" (Rincón, 2006, p. 59). De hecho, gran parte de los grupos juveniles contestatarios y fuertemente politizados, manifiestan su crítica e inconformismo (por ejemplo, los raperos, los hip hoperos, los punketos) a través de indumentarias, poses, actitudes y aditamentos que se expresan a través del cuerpo. En la mayoría de culturas juveniles, el cuerpo se revela como espacio político, como subvertor de reglas anodinas e hipócritas, como frontispicio que invita a ingresar a la casa donde se forja la rebelión, como verdadero y único lugar de libertad que queda en el mundo, como medio de comunicación e interacción.

Pero así como las tecnologías se han apoderado del cuerpo y su memoria, lo mismo ha ocurrido con los saberes que hay que recordar. La sociedad del entretenimiento y las culturas mediáticas requieren saberes simples y superficiales que no cuestionen ni se resistan al espectáculo. Por tanto, el pensamiento leve, difuso y aleatorio es una condición para entender la lógica de esta sociedad. De esta forma, fenómenos como la interactividad, la virtualidad y, en general, todas las formas de expresión de las narrativas mediáticas, han ido configurando nuevos modelos mentales mediados por los media y formas de procesamiento de información antes inexistentes. Estas alfabetizaciones posmodernas están promoviendo una reestructuración de la percepción mediante la formación de formatos cognitivos que posibilitan no sólo adoptar diversos puntos de vista con respecto a la realidad, sino razonar mediante algoritmos que se asimilan más a procedimientos abductivos que deductivos o inductivos. No sin razón McLaren (1992) considera que los medios y las nuevas tecnologías provocan nuevas formas de conocimiento a la manera de una pedagogía perpetua que siempre está renovando, no sólo contenidos y problemas, sino exigiéndole al sujeto nuevos formatos cognitivos que se ajusten a esos cambios constantes.

En este sentido, el sociólogo italiano Luciano Gallino (1990) ha propuesto el modelo MMMM (modelos mentales mediados por los media) para explicar cómo se han empezado a desarrollar una serie de esquemas interpretativos como resultado de los modelos mentales que las tecnologías y las culturas mediáticas difunden sin tregua, semejantes a los frames o formatos propuestos por Erwin Goffman en su momento. Estos modelos no sólo son coherentes con las lógicas de las narrativas hipertextuales e hipermediales, sino que son fundamentalmente esquemas de interpretación situada en cuyo "guión" están inscritas las fases o acciones para que el sujeto pueda avanzar en las tareas que se le proponen. Esto nos lleva a entender que el pensamiento que promueve lo mediático se inscribe entonces en una cultura de la velocidad, la simultaneidad y la paradoja; y sus modos de subjetivación se producen a través de una yuxtaposición entre la frivolización de la vida y la búsqueda de información certera, entre la exacerbación de lo superficial y la proliferación de significantes, entre los formatos tecnológicos y la imaginación surrealista de sus usuarios.

Como es fácil inferir, éstas nuevas formas de pensamiento mediado por los medios aún no han llegado a la escuela. Es así como las subjetivaciones y subjetividades políticas desarrolladas y construidas desde colectivos de enunciación con saberes diferentes a los formales e instituidos, que en la escuela no son otros que los estándares, las competencias y las teorías abstractas, son descalificadas y percibidas como peligrosas, irracionales, subversivas $y$, en el peor de los casos, terroristas. Apartarse del saber formal, analítico y deductivo, y tratar de introducir otros saberes que le apuestan a lo múltiple, a los bordes, a la complejidad, a lo mediático, o simplemente al sentido común, al saber ancestral o al imaginario colectivo, implica ser discriminado o ridiculizado, sancionado o vetado (como es el caso de algunos grupos juveniles que investigan sobre 
lenguas vernáculas, saberes atávicos o monumentos instituyentes).

La escuela colombiana aún no ha entendido el paso que el mundo contemporáneo y la cultura mediática ha dado a lo que Lipovetsky (2005) ha denominado como sociedad posmoralista, la cual describe perfectamente la moral juvenil. "Es una sociedad que repudia la retórica del deber austero, integral, maniqueo y, paralelamente, corona los derechos individuales a la autonomía, al deseo, a la felicidad... Es una sociedad que, lejos de exaltar los órdenes superiores, los eufemiza y decredibiliza, una sociedad que desvaloriza el ideal de abnegación estimulando sistemáticamente los deseos inmediatos, la pasión del ego, la felicidad intimista y materialista”.

La memoria colectiva en la escuela pasa entonces por la comprensión de la transformación que los valores están atravesando,

del por qué hay valores que se pierden y de cuáles son los que se ganan, los que se han gastado y los que se recrean. Porque en todo caso donde se están acabando los valores no es entre los jóvenes, ellos están haciendo visible lo que desde hace tiempo se ha venido pudriendo en la familia, en la escuela, en la política (Martín Barbero, 1998).

Y a ésta transformación de los imaginarios axiológicos y normativos, la escuela se mantiene tozudamente ajena, descalificadora y excluyente. Mientras que en la familia, la calle y sobre todo en la cultura mediática se ha producido un des-ordenamiento cultural, simbólico y valorativo, la escuela persiste en negar, obliterar y castigar lo que los niños y jóvenes tienen como obvio y taxativo en sus prácticas interpretativas cotidianas. Como dice Meyrowitz (1995; citado por Martín Barbero, 1998),

Lo que hay de verdaderamente revolucionario en la televisión es que ella permite a los más jóvenes estar presentes en las interacciones de los adultos. Es como si la sociedad entera hubiera tomado la decisión de autorizar a los niños a asistir a las guerras, a los entierros, a los juegos de seducción eróticos, a los interludios sexuales, a las intrigas criminales. La pequeña pantalla los expone a los temas y comporta- mientos que los adultos se esforzaron por ocultarles durante siglos.

Otra forma en que se tergiversa la memoria colectiva y, en general, la memoria histórica en la escuela, es a través de los denominados sentimientos morales. Señalados inicialmente por Hume pero olvidados durante siglos, han sido retomados por autores como Ch. Taylor (1996) y Strawson (1995). En términos generales, se han propuesto tres sentimientos morales básicos: el resentimiento, la indignación y la culpa, de los cuales se derivan, a manera de contraparte, la gratitud, la solidaridad y el perdón.

De acuerdo con diversos trabajos y pruebas sobre desarrollo y educación moral, los regímenes de subjetivación moral en la escuela hacen un manejo de estos sentimientos morales fundamentalmente en dos sentidos: o bien articulados a la moral católica, en donde los imaginarios morales actúan como mecanismos de protección y exclusión frente a lo diverso, lo diferente y lo secular; o bien, racionalizados en niveles o periodos que indican la forma y el contenido de cómo se debe resolver un dilema moral. En otras palabras, los sentimientos morales son mixtificados, interpretados y juzgados por criterios no humanos sino divinos, o, entendidos en términos universales, abstractos y racionalistas, en donde la alteridad, y en general todas las formas de relación con el otro queda obliterada y subordinada al nivel de desarrollo cognitivo del sujeto. De esta forma, el resentimiento, por ejemplo, tan determinante en los procesos de justicia y reparación, aparece cuando el sujeto es afectado por otro a quien se le atribuye responsabilidad sobre el daño causado, es considerado negativo bien sea porque conlleva sentimientos vengativos o revanchistas (en una perspectiva cívico-religiosa), o bien, porque ese sentimiento está revelando que el sujeto se encuentra en un nivel preconvencional en donde todavía está razonando con los criterios de la ley del talión. En síntesis, el manejo de los sentimientos morales que se hace en la escuela no sólo perpetúa lo que Lipovetsky llamara "el crepúsculo del deber", que son las formas sociales de lo religioso, como la justicia divina y la estatización de las costumbres, 
sino en la racionalización prescriptiva de la norma a través de la ética de una inexistente autonomía y un universalismo kantiano ajenos a nuestra realidad política y cultural.

\section{Conclusiones: la escuela como emprendedora de la memoria individual y colectiva}

Cuando se pasa revista por las diversas perspectivas disciplinares que han estudiado la memoria se puede inferir, en una primera instancia, que hay dos tendencias casi antagónicas en su abordaje: la individual, que la entiende como dispositivo de codificación y almacenamiento de información y comunicación; y la socio-histórica, que la asume como imperativo ético y político que posibilita el devenir identitario de una nación o un colectivo social. Sin tener que profundizar mucho ${ }^{9}$, es fácil deducir por sus sistemas curriculares, sus prácticas pedagógicas o sus proyectos de investigación, que la escuela, con muy pocas excepciones, no ha incorporado a sus procesos de enseñanza y aprendizaje ninguna de estas dos tendencias. Las razones son múltiples y heterogéneas, van desde el encorsetamiento curricular o institucional que se impone a los docentes, hasta el simple desconocimiento de ésta problemática, pasando por el desinterés, la falta de recursos o el peligro que acecha en cada esquina de la ciudad. No obstante, con base en los planteamientos expuestos, se pueden proponer los siguientes aspectos a tener en cuenta para los retos que la memoria tiene en educación:

1. Los procesos de filtración de información y comunicación en la Web son pragmáticos, arbitrarios, subjetivos, y muchas veces inconscientes. No existen -ni existirán-criterios de selección y filtrado de la información, ya que

9 Son prácticamente inexistentes los proyectos escolares sobre la recuperación de la memoria colectiva o sobre el manejo y filtración de la información en la Web por parte de los estudiantes, con excepción del colectivo de profesores PASAPALABRA y algunas experiencias tangenciales auspiciadas por el IDEP en el proyecto Escuela-Ciudad-Escuela en las que, a través de salidas pedagógicas, se incluye la visita a monumentos y sitios con valor histórico o cultural de la ciudad, pero que evidentemente no tienen una intención ético-política como la plantean sus investigadores, $y$ como aquí se ha esbozado. pueden ser variados y/o coyunturales: el conocimiento en profundidad del tema, los intereses subjetivos (que permiten la adquisición de mayor capital simbólico o material), las demandas de las comunidades de práctica o de recuerdos en las que se mueve el individuo, la necesidad de reconocimiento y de hacer pública su privacidad e intimidad, el juego y la distracción, el daño y la maledicencia, la denuncia y la crítica, la ironía y el chiste, en fin, cualquier cosa. ¿Qué hacer?

La perspectiva de la memoria compartida puede resultar aquí de gran ayuda. En efecto, si los recuerdos se reconstruyen en función de mediaciones sociales específicas, se hace necesario explicitar algunas de las formas como los estudiantes comparten sus recuerdos, su organización retórica (esto es, sobre las versiones contradictorias del pasado: a quién culpar, perdonar, agradecer, etc.), qué eventos o acontecimientos, por efímeros y vertiginosos que sean, son relevantes como criterios de selección y uso de la información de la información y la comunicación. Esta explicitación no pretende controlar o regular las elecciones morales que subyacen a ese proceso de filtración, sino, precisamente, compartir los marcos sociales vigentes y flotantes de la memoria ${ }^{10}$, para poder entender esa intersección entre la memoria individual y la memoria colectiva que en ese momento se está operando. En el fondo, de lo que se trata no es otra cosa que la reconstrucción colectiva del recuerdo, el recordar juntos, a partir de la aplicación de las estrategias que tiene la memoria compartida, a ese gran Funes que es la web, e internet en general. Al fin y al cabo, es a través del recordar juntos como podemos entender la integración a una determinada modalidad de práctica social,

10 Empleo aquí, a pesar de todas sus limitaciones y críticas (Jelin [2002], Oviedo [2009]), la noción de marcos sociales de la memoria de Halbwachs, ajustándolo a las especificidades del planteamiento que estoy haciendo, esto es, al carácter evanescente de estos marcos, o de parte de ellos, cuando son utilizados en la web. 
y hacer inteligible la coherencia y el sentido de continuidad que los usuarios de la red le dan a sus vidas.

2. La escuela hace usos buenos y malos de la memoria colectiva. Ninguna institución social -la familia, el estado, el ejército, etc.- y con mayor razón la escuela, pueden soslayar su condición de emprendedores de la memoria. Este concepto, introducido por Jelin (2002), se refiere a aquellos agentes que pretenden $\mathrm{e}$ incitan al reconocimiento y legitimidad ética y política de una versión del pasado, a la vez que mantienen la atención social sobre su actividad. En otras palabras, los emprendedores de memoria determinan el uso ético-político y público que se hace de la memoria y, por tanto, algunos hacen un uso bueno, como por ejemplo valerse del pasado para entender e iluminar el presente, o emplear las lecciones de las injusticias vividas para combatir las actuales, o, por el contrario, algunos pueden hacer un uso malo, como someter el pasado al presente o utilizar el pasado con fines lucrativos, morales o de disciplinamiento ${ }^{11}$.

11 Estos usos y abusos de la memoria fueron propuestos por Todorov (1998, citado por Jelin, 2002) y permiten entender no sólo las manipulaciones y tergiversaciones que se hacen de la memoria desde las diversas instancias de poder, sino desde la ingenuidad, la ideología, el imaginario social dominante y el sentido común, tan frecuentes en nuestros maestros de básica y media.

\section{Bibliografía}

Braunstein, N. (2008). Memoria y espanto o recuerdo de infancia. México: Siglo XXI.

Eco, U. (1999). A todos los efectos. En J. C. Carrière et al. El fin de los tiempos. Barcelona: Anagrama.

Gallino, L. (1990). El problema MMMM (Modelos mediados por los media) en AAVV. Videoculturas de fin de siglo. Madrid: Cátedra.

Giddens, A. (1995). La transformación de la identidad. Madrid: Cátedra.

Jelin, E. (2002). Los trabajos de la memoria. Madrid: Siglo XXI.
La escuela, como uno de los emprendedores de memoria más legitimado e institucionalizado -al fin y al cabo es la única institución autorizada para enseñar historia-, se ve abocada cotidianamente a tales dilemas morales y políticos de la memoria, que ha terminado por obviarlos y refugiarse en su uso literal, en el que se entienden los hechos de forma aislada, intransferibles e inconexos, que no conducen a nada más allá de sí mismos. Ahora bien, si la escuela pretende hacer un uso bueno de la memoria, los profesores deben involucrarse personalmente en los proyectos de recuperación o rememoración, comprometiendo a docentes de las otras áreas, generando participación y distribuyendo el trabajo, para que el pasado se convierta en un precepto de acción e interpretación del presente, reordenando y desordenando los hechos, propiciando la escucha de las voces acalladas, creando espacios intersubjetivos a través de recuerdos comunes, compartiendo narrativas de lo vivido. 그
Middleton, D. y Edwards, D. (Compiladores). (1992). Memoria compartida. La naturaleza social del recuerdo y el olvido. Barcelona: Paidós.

Newell, A. (1980). Inteligencia artificial y el concepto de mente. Valencia: Revista Teorema.

Martín-Barbero, J. (1998). Jóvenes: Des-orden cultural y palimpsesto de identidad. En H. Cubides et al. Viviendo a toda. Bogotá: DIUC, Universidad Central.

Lipovetsky, G. (2005). El crepúsculo del deber. Barcelona: Compactos Anagrama.

Oviedo, A. (2009). Apuntes para el debate. Memoria colectiva y movimientos sociales. En A. Jiménez y 
F. Guerra (Compiladores). Las luchas por la memoria. Bogotá: Universidad Distrital Francisco José de Caldas. Ipazud.

Penrose, R. (1991). La nueva mente del emperador. Barcelona: Grijalbo Mondadori.

Rincón, O. (2006). Narrativas mediáticas. O cómo se cuenta la sociedad del entretenimiento. Barcelona: Gedisa.

Ryan, M. (2004). La narración como realidad virtual. Buenos Aires: Paidós.

Searle, J. (2006). La mente. Una introducción. Bogotá: Norma.
Serna, A. (2009). Introducción: amnesias y anamnesias. Algunos desafíos para los estudios de la memoria. En A. Serna (Compilador). Memorias en crisoles. Bogotá: Universidad Distrital Francisco José de Caldas. Ipazud.

Shacter, D. (1999). En busca de la memoria. Barcelona: Ediciones Grupo Zeta.

Strawson, P. (1995). Libertad y resentimiento. Barcelona: Paidós.

Taylor, C. (1996). Fuentes del yo. La construcción de la identidad moderna. Barcelona: Paidós. 